Article

\title{
Implementation of a Surface Water Extent Model in Cambodia using Cloud-Based Remote Sensing
}

\author{
Christopher E. Soulard ${ }^{1, *}$, Jessica J. Walker ${ }^{2}\left(\mathbb{D}\right.$ and Roy E. Petrakis ${ }^{3}(\mathbb{C}$ \\ 1 U.S. Geological Survey, Western Geographic Science Center, P.O. Box 158, Moffett Field, CA 94035, USA \\ 2 U.S. Geological Survey, Western Geographic Science Center, Tucson, AZ 85719, USA; jjwalker@usgs.gov \\ 3 Contractor to the U.S. Geological Survey, Western Geographic Science Center, Tucson, AZ 85719, USA; \\ roypetrakis@gmail.com \\ * Correspondence: csoulard@usgs.gov; Tel.: +1-650-439-2317
}

Received: 5 February 2020; Accepted: 9 March 2020; Published: 19 March 2020

\begin{abstract}
Mapping surface water over time provides the spatially explicit information essential for hydroclimatic research focused on droughts and flooding. Hazard risk assessments and water management planning also rely on accurate, long-term measurements describing hydrologic fluctuations. Stream gages are a common measurement tool used to better understand flow and inundation dynamics, but gage networks are incomplete or non-existent in many parts of the world. In such instances, satellite imagery may provide the only data available to monitor surface water changes over time. Here, we describe an effort to extend the applicability of the USGS Dynamic Surface Water Extent (DSWE) model to non-US regions. We leverage the multi-decadal archive of the Landsat satellite in the Google Earth Engine (GEE) cloud-based computing platform to produce and analyze 372 monthly composite maps and 31 annual maps (January 1988-December 2018) in Cambodia, a flood-prone country in Southeast Asia that lacks a comprehensive stream gage network. DSWE relies on a series of spectral water indices and elevation data to classify water into four categories of water inundation. We compared model outputs to existing surface water maps and independently assessed DSWE accuracy at discrete dates across the time series. Despite considerable cloud obstruction and missing imagery across the monthly time series, the overall accuracy exceeded $85 \%$ for all annual tests. The DSWE model consistently mapped open water with high accuracy, and areas classified as "high confidence" water correlate well to other available maps at the country scale. Results in Cambodia suggest that extending DSWE globally using a cloud computing framework may benefit scientists, managers, and planners in a wide array of applications across the globe.
\end{abstract}

Keywords: surface water; inundation; land change; remote sensing; Landsat; Google Earth Engine; Southeast Asia; Cambodia

\section{Introduction}

Surface water dynamics are typically monitored through time series of water flow derived from stream gage data. The assembly of accurate, precise, and frequent (sub-daily) measurements of streamflow in diverse watercourses is invaluable for managing water supplies and anticipating flood events. However, gage data are geospatially sparse, non-existent, or not publicly available in many parts of the world, and the number of stream gages is decreasing globally [1-3]. Even when gage data are available, their applicability is limited by their representation of discrete samples of a hydrologic network that varies across time and space [4]. As such, point-based stream measurements do not directly provide the spatial extent of surface water change (e.g., flood footprints) on the landscape. Although stream gage measurements are commonly incorporated into simulations of inundation events, models do not necessarily reproduce realistic flood events or transfer easily to different locations 
unless calibrated with actual observations or ancillary data. The spatially explicit mapping of surface water change is recognized as an acceptable method to empirically train, validate, and improve flood inundation predictions [5]. In addition to hydroclimatic research focused on droughts and flooding, accurate maps of surface water extent are also valuable inputs into analyses of flora and fauna species' sensitivity [6,7] and assessments of hazard risk at the community scale [8,9], as well as in water management and economic planning and forecasting [10].

In recent years, a variety of space-based approaches have been applied to measure, map, and model surface water distributions in various geographies across the globe [11]. Mapping water in parts of the world where relevant data resources are scarce and rivers are largely ungaged has been performed using optical [12] and microwave [13] imagery. The Dartmouth Flood Observatory has pursued each of these techniques to meet large-scale mapping goals [14-16]. Systematic surface water products are becoming increasingly available at global scales. In 2011, the Hydrology Laboratory at NASA's Goddard Space Flight Center launched the Global Flood Mapping System, which provides daily global surface water information at 250-m spatial resolution using Moderate Resolution Imaging Spectroradiometer (MODIS) data [17]. Similarly, the European Commission's Joint Research Centre (JRC) partnered with Google Earth Engine (GEE) [18] to use the Landsat satellite archive to produce monthly global surface water maps at 30-m spatial resolution (currently available from 1984-2018) [19]. The drawback to mapping surface water extents with optical imagery is that cloud cover may prolong revisit cycle times and hinder the detection of low-frequency, short-duration surface water changes often associated with flood events [19]. Nevertheless, many of these products are widely available and represent a potential source of information to help manage phenomena such as flood risk, drought, agricultural irrigation, and habitat conservation [20-22].

A new resource in the field of surface water mapping is the USGS Dynamic Surface Water Extent (DSWE) map product, released as an analysis-ready data product (ARD) in 2018. DSWE raster layers represent surface water inundation in Landsat 30-m pixels (December 1982-present). To classify water bodies, the DSWE algorithm applies a series of tests based on water and vegetation indices derived from Landsat spectral information $[23,24]$. The DSWE water classes provide gradations-high confidence, wetlands, low-confidence-that may allow more nuanced insights into the character of surface water inundation than binary classifications of water presence or absence. Recent efforts to compare JRC and DSWE maps in California's Central Valley [25] suggest that DSWE maps produced in GEE can consistently replicate data from the Landsat-based ARD collection with more than 90\% agreement. Walker et al. [25] also found that JRC- and GEE-produced DSWE maps result in highly correlated time series. As with other optical-based methods for surface water detection, DSWE maps are vulnerable to cloud obstruction, which means that not every pixel may be imaged clearly during a Landsat satellite overpass. While optical approaches may be imperfect, surface water maps provide snapshots that can be assembled into dense time series and help serve global applications that require surface water map inputs.

DSWE products were developed for and prototyped in the United States, but published methods $[26,27]$ present an opportunity to extend surface water mapping into new geographies. Non-US locations are attractive areas for evaluating the DSWE algorithm because of the possibly different degree of Landsat availability [28] and the need for a consistent means of quantifying hydrological dynamics in the absence of streamgage data. Early efforts have been made to apply DSWE in the Canadian tundra [29], but ample opportunities exist to create a scalable workflow to extend the DSWE model elsewhere and test its performance against other data sources. The availability of cloud-computing resources such as GEE enables the processing and evaluation of DSWE products over large areas (e.g., national scales).

Our objective with this effort is to use GEE to demonstrate the applicability of the DSWE model for geographies outside the United States. We implement DSWE for Cambodia, a flood-prone country in Southeast Asia that lacks a comprehensive stream gage network. Surface water extremes such as floods and droughts affect human populations and economic activities in much of Cambodia on an 
annual basis [30]. These events endanger communities [9], ruin crop yields [11], and contribute to water-borne diseases [31]. For example, above-average rainfall in August and September 2011 led to flooding across large parts of the country, causing 52,000 household evacuations, 250 deaths, and an estimated $>\$ 100$ million in damages [32]. The increased flood frequency and magnitude in recent years necessitates a more detailed understanding of the rates, patterns, and causes of hydrologic change throughout Cambodia [33]. Despite the flood-prone landscape, limited resources exist for monitoring surface water change and river discharge throughout the entire country. This vulnerability to flooding and concurrent lack of systematic information about surface water dynamics make Cambodia an ideal site for the implementation of the DSWE model.

To investigate the usefulness of DSWE time series in Cambodia, we generate both a comprehensive set of monthly inundation maps that we evaluate against corresponding JRC products and a set of annual composites maps that we compare to measures of vegetation greenness derived from Landsat. We also assess the accuracy of the DSWE annual products. The results of these tests will help us to assess the feasibility of the GEE implementation of DSWE for extending surface water mapping efforts in locations where satellite imagery is readily available but other constraints may exist, such as only having sparse gage networks or limited data processing tools.

\section{Methods}

\subsection{Study Area}

Southeast Asia is considered one of the most flood-prone regions in the world [34]. Much of the landscape is characterized by low-lying plains that become inundated seasonally (between August and November) by monsoons originating from the Indian Ocean and the Pacific Ocean. Long stretches of the Mekong River, the 12th longest river in the world, flow through Cambodia, where it splits into the Tonle Sap, Bassac, and Lower Mekong rivers. Tonle Sap River feeds into Tonle Sap Lake, the largest freshwater lake in Southeast Asia. The lake's surface area varies substantially throughout the year, ranging from a minimum footprint of $2500 \mathrm{~km}^{2}$ to a maximum footprint of around $16,000 \mathrm{~km}^{2}$ during the monsoon season (Figure 1) [30]. The area surrounding Tonle Sap Lake historically consisted of seasonally inundated shrubland and forests; it is designated by the World Wildlife Fund as a swamp forest [35]. Most of the floodplain has been cleared for rice cultivation and human settlements. Cambodia's capital, Phnom Penh, is located at the confluence of the Mekong and Bassac Rivers. People here, as well as in the rest of the floodplain, are adapted to periodic flooding. To a large degree, the economy (i.e., agriculture) relies on seasonal inundation cycles. However, those communities near water bodies are still susceptible to extreme flooding events. Applying a multi-class DSWE model at a monthly scale provides an opportunity to understand the scale and timing of partially and fully inundated agricultural fields within the former swamp ecoregions that represent the Tonle Sap floodplain.

\subsection{Generation of Dynamic Surface Water Extent Maps in Google Earth Engine}

All imagery and elevation raster processing steps were completed in Google Earth Engine (GEE), a cloud-based computational platform that enables the processing and analysis of entire remote sensing image archives [18]. A growing body of literature highlights how GEE has been applied to analyze landscape change across multi-decadal Landsat collections [36,37]. Adapting code developed as part of Walker et al. [25], we created scripts in the GEE JavaScript application programming interface to replicate DSWE version 2.0 maps [38,39]. DSWE classifies pixels unobscured by cloud, cloud shadow, or snow into five categories of ground surface inundation (Table 1); in addition to not-water (class 0 ) and water (class 1), the DSWE algorithm distinguishes pixels that are less distinctly inundated (class 2: "moderate confidence"), comprise a mixture of vegetation and water (class 3: "potential wetland"), or are of marginal validity (class 4: "water or wetland-low confidence"). We assume that these more nuanced classes might be of value in Cambodia given the frequent inundation of vegetated areas. 


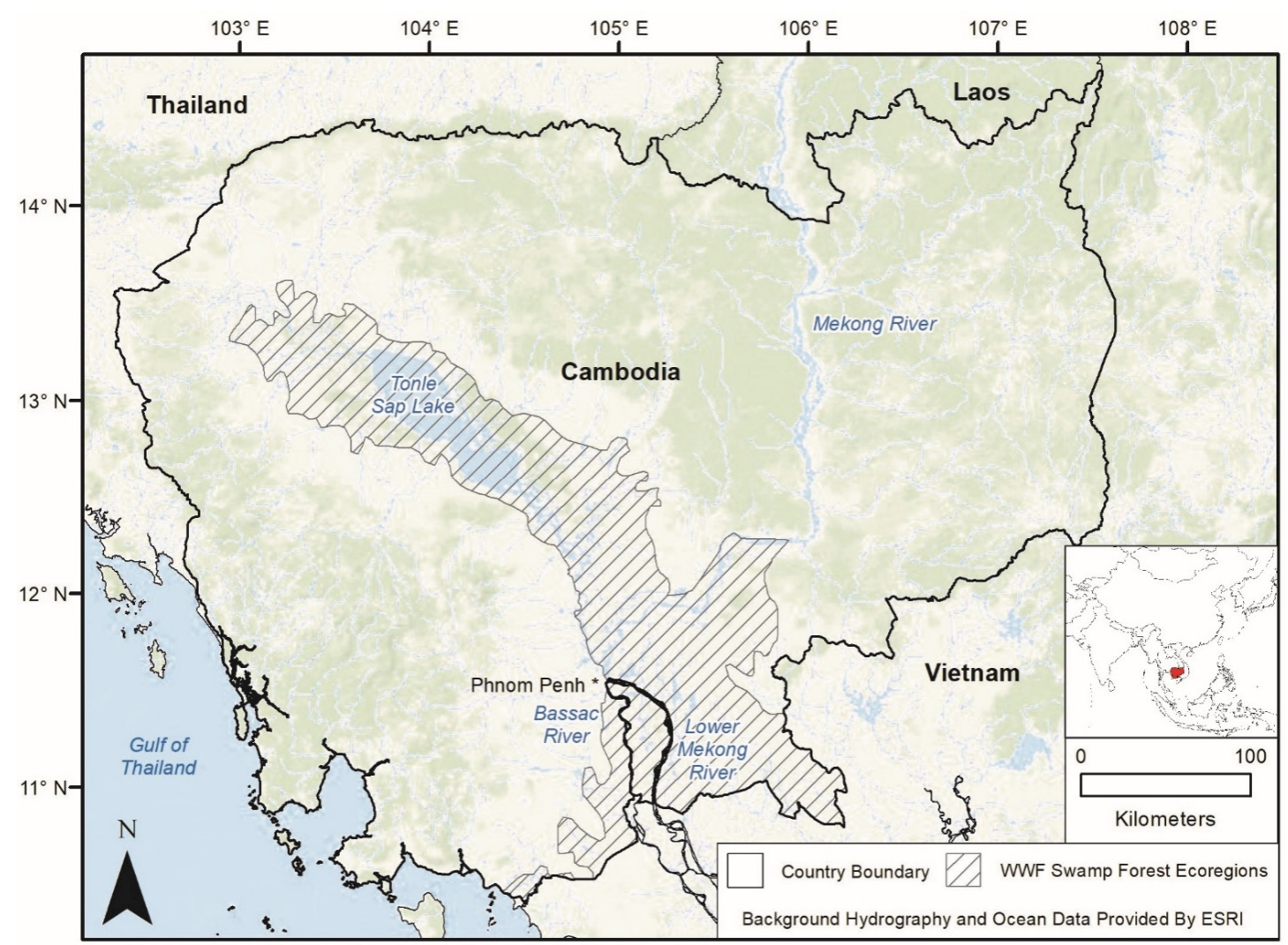

Figure 1. The study area encompasses the country of Cambodia. The lower Mekong River and a large floodplain surrounding Tonle Sap Lake have highly seasonal inundation dynamics.

Table 1. Dynamic Surface Water Extent (DSWE) and Joint Research Centre (JRC) classes.

\begin{tabular}{ccc}
\hline Dataset Name & Class & Class Description \\
\hline DSWE & 0 & Not water \\
& 1 & Water-high confidence \\
& 2 & Water-moderate confidence \\
3 & Partial surface water pixel \\
& 4 & Water or wetland-low confidence \\
& 9 & Cloud, cloud shadow, or snow \\
JRC & 0 & No data \\
& 1 & Not water \\
& 2 & Water \\
\hline
\end{tabular}

The technical documents outline the model process steps [26,27] which use Landsat visible, near infrared (NIR), and short-wave infrared (SWIR1 and SWIR2) bands to create five water and vegetation-specific indices: Modified Normalized Difference Wetness Index (MNDWI), Multi-Band Spectral Relationship Visible (MBSRV), Multi-Band Spectral Relationship Near-infrared (MBSRN), Automated Water Extent Shadow (AWESH), and Normalized Difference Vegetation Index (NDVI). Digital elevation model (DEM)-derived topographic layers assist with inundation determination; hillshade is used to correct for classification confusion due to terrain shadowing, and slope is applied via decision rules to mask out classification error. DSWE reassigns pixels with slopes greater than $10 \%$ to "not water" depending on the assessed water class. Terrain is less of a consideration in Cambodia, which is relatively flat, but remains relevant in other possible geographic applications. The indices are evaluated against empirically derived thresholds and summed to create a composite pixel score, which 
is assigned to a water class via a look-up table. The DSWE product description documents provide more detailed information on the model tests and thresholds [26,27].

We adapted the validated model created in [25] for implementation outside the United States by deriving hillshade and slope terrain products from 30-m Shuttle Radar Topography Mission [40] elevation data rather than the 10-m National Elevation Dataset available solely in the United States [41]. Additional changes include a narrowed window of analysis (1988 start date) to avoid gaps in the Landsat 5 chronology in Cambodia and the aggregation of surface water maps to an annual scale.

Using the modified GEE script, we produced 372 monthly and 31 annual composite maps for January 1988 through December 2018 for all of Cambodia. Annual maps were produced as a supplement to the monthly maps to generate cloud-free, country-wide snapshots and general summary statistics. To assemble the monthly composites, we created DSWE layers for every retrieved Landsat image in Cambodia from 1988 to 2018 and retained the highest confidence classification in each month. For instance, a pixel with class 1 ("high confidence") in one image and class 2 ("moderate confidence") in another retained a final category of class 1 . All water classes took precedence over cloud contamination, while pixels masked for slope maintained that status in the final monthly compilation. The resulting GEE product was output as a single image with 372 bands, each representing a different month between 1988 and 2018. Monthly data and GEE codes are available as Supplementary Materials. The same process was repeated to create annual composites, where the highest confidence classes were retained at the pixel level by looking at all images throughout each year. The resulting product was output as a single image with 31 bands, each representing a maximum water extent for each year over the observed period.

\subsection{Comparison of DSWE to NDVI, Slope, and JRC Surface Water Maps}

We evaluated the accuracy of the DSWE outputs by performing multiple comparisons of the monthly products against alternate sources of surface water information. We calculated the range of NDVI and slope values by randomly sampling 10,000 points from each DSWE water class $(n=40,000)$ in January 1989 and January 2015 to investigate the nuanced differences of the DSWE algorithm's mixed vegetation and slope for water categories at in months with minimal cloud cover. To evaluate the consistency of independent assessments of surface water coverage, we compared monthly DSWE maps to monthly JRC maps for the period 1988-2018. JRC represents the best proxy where gage data are lacking, and global validation efforts indicate that JRC accurately maps surface water [19]. JRC is produced at monthly timesteps using Landsat 30-m imagery, similar to the DSWE model implementation in this study, but JRC uses a decision-tree model to classify pixels as either water or non-water in a calendar month [19]. We calculated the linear Pearson correlation between pixel totals in the "high confidence" water class in DSWE and the "water presence" class in JRC on an aggregate country-wide scale in each month for 1988 to 2018. We repeated the process within World Wildlife Fund (WWF) ecoregions that contain the country's floodplain to better understand correspondence in areas with higher rates of inundation [35]. The WWF ecoregions are an assemblage of 867 units spanning the globe that group land areas into homogenous biogeographic units. In other words, each ecoregion shares similar species, dynamics, and environmental conditions. The ecoregions applied in this study are characterized as swamp shrublands and forests and capture the floodplain area of Tonle Sap Lake.

\subsection{Multi-Date Accuracy Assessment of DSWE Water Classes}

The final versions of the annual DSWE maps were evaluated against higher-resolution Sentinel-2 $(10 \mathrm{~m})$ and Landsat $(30 \mathrm{~m})$ reference imagery. We performed a traditional accuracy assessment by manually interpreting reference pixels as "low/no water", "moderate-confidence water", or "high-confidence water" classes [42]. This modification of the original DSWE scheme was necessary given the difficulty in visually distinguishing "no water" and "low water" classes in the reference imagery. We performed an analogous aggregation of DSWE water confidence classes in the annual 
product; the "no water" (class 0) and "water or wetland-low confidence" (class 4) classes were merged to correspond to a "low/no water" class, and "moderate confidence" (class 2) was merged with "potential wetland" (class 3) to correspond to a "moderate-confidence water" class. The "high-confidence" water (class 1) was retained on its own.

A random sample of 300 points was used to assess accuracy in 1989, 2015, and 2018. The points were proportionally distributed among the classes to represent the composition of water inundation across the landscape, as is standard practice in land cover accuracy tests [42]. We selected WWF ecoregion boundaries [35] that delineate the primary inundation zones of Cambodia as the stratum for our analysis. These zones include most of the Tonle Sap floodplain (Figure 1). The sample years were selected because they represent the beginning and the end of the study period and include at least one assessment date that has high-resolution $(10 \mathrm{~m})$ reference imagery available.

The reference label for each point was manually interpreted by a trained image interpreter on the basis of multi-band image composites assembled in and downloaded from Google Earth Engine using 30-m 1989 Landsat TM imagery, 30-m 2015 Landsat OLI imagery, and 10-m 2018 Sentinel-2 imagery, each with less than $1 \%$ cloud cover. The same 300 reference points were reused and reinterpreted for each of the analysis years. The three (low, moderate, high) water classes were visually determined based on approximate thresholds of $0-15 \%$ water, $15-60 \%$ water, and $60-100 \%$ water, respectively. A 250-m window was applied to provide context for the class labeling, and to accommodate location errors between ground reference points and the DSWE map. Similarly, the National Land Cover Dataset accuracy assessment effort [43] applied a $3 \times 3$ classification window to provide interpreters with information on sample neighborhoods. Finally, we calculated the producer's and user's accuracy values, as well as the overall accuracy and kappa values for each year [44]. Overall accuracy is a reflection of both the producer's and user's accuracy. Producer's accuracy accounts for how many points were omitted from the correct reference class (producer's accuracy $=100 \%$ - omission error). User's accuracy accounts for how many points were committed (or assigned) to incorrect reference classes (user's accuracy $=100 \%$ - commission error). The kappa test is a measure of how the classification performed (overall accuracy) compared to randomly assigning class values (expected accuracy). Values range from $-100 \%$ to $+100 \%$ and higher positive values suggest that the classifier performs better than a random classification.

\subsection{Exploration of DSWE Class Dynamics}

After verifying the validity of the DSWE maps in Cambodia, we explored the distribution and temporal dynamics of the individual classes across the country on a monthly, seasonal (wet: May through October; dry: November through April), and annual basis. For each temporal period, we calculated the average, minimum, and maximum surface water area in each class. Of particular interest were the dynamics of the individual classes with respect to one another.

\section{Results}

\subsection{Generation of Monthly and Annual Composite DSWE Products}

Producing a consistent time series of monthly surface inundation maps for Cambodia at the country scale was challenging given gaps in the Landsat data record and the frequency of cloud obstruction. Of the 372 possible monthly composite outputs, 151 had more than 20\% "no data" due to missing data. Similarly, 148 months had more than $20 \%$ "no data" due to cloud obstruction. An assessment of class 9 relative to the total land area indicates that cloud cover averaged $34 \%$ of the country's land area during the wet season (May through October) and 14\% during the dry season (November through April). We were left with 131 months of data once we removed any month affected by excessive missing imagery or clouds (an average of 4 months available per year) (Figure 2). The screening process effectively eliminated all September maps across the time series and all but one August map. 


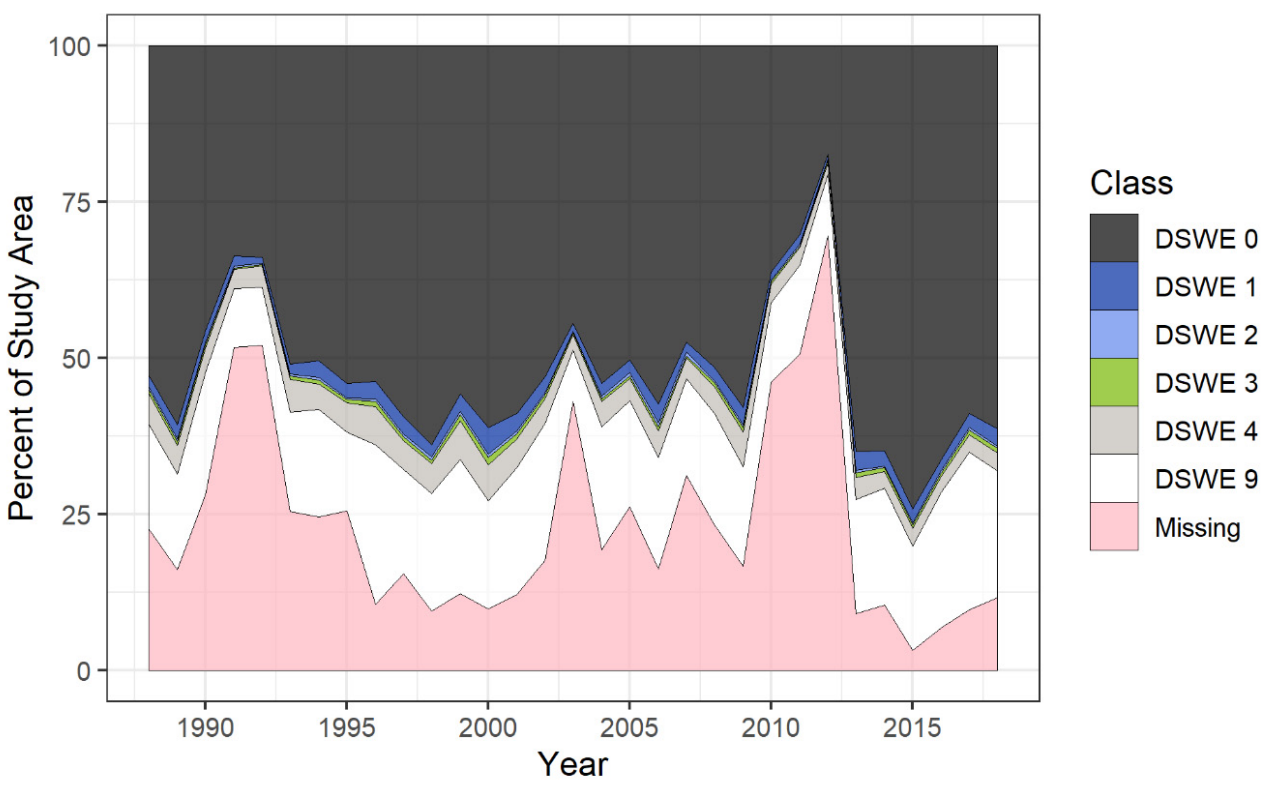

Figure 2. DSWE classes aggregated by year as a proportion of the study area. The data distribution illustrates the influence of clouds (DSWE class 9) and gaps in the Landsat data time series ("Missing"). Only those months with a high proportion of usable data across the study area (i.e., $>20 \%$ clear of clouds and missing data) were retained for subsequent analyses, and 2012 was removed entirely.

The 31 annual maps of maximum detected water extent present a cleaner time series of water dynamics for the entire country with a minimum of cloud obstruction. On average, cloud and cloud shadow cover represent $<1 \%$ of Cambodia's land area for the annual composites. Outliers are in annual maps from 2011 (4\% cloud cover) and 2012 (17\% cover) due in part to lower image availability as the Landsat 5 data stream ended. We excluded all 2012 maps (monthly and annual) from our analysis due to excessive amounts of missing data and extensive cloud cover. These maps provide an opportunity to investigate general trends such as the linkage between high and low surface water totals with wetter-and-drier rainfall years. However, intra-year dynamics are lost in the temporal aggregation process in yearly composites.

\subsection{DSWE Class Dynamics in Cambodia}

Moderate confidence water categories (classes 2 and 3), which include pixels with both water and vegetation, have lower area totals than the "high confidence" category (class 1) in the monthly, seasonal, and annual maps. Class 1 averages $7200 \mathrm{~km}^{2}$ in monthly maps generated during the wet season (May through October) and only $5000 \mathrm{~km}^{2}$ in maps representing the dry season (November through April). The combination of classes 2 and 3 averages less than $40 \%$ of those totals: $3100 \mathrm{~km}^{2}$ and $1700 \mathrm{~km}^{2}$ respectively (Figure 3). Over the entire study period, the minimum surface water area for class 1 was approximately $1600 \mathrm{~km}^{2}$, while the maximum surface water area reached $17,000 \mathrm{~km}^{2}$ across the monthly records. Conversely, the minimum area for classes 2 and 3 (combined) was $350 \mathrm{~km}^{2}$, while the maximum area was $6800 \mathrm{~km}^{2}$.

Although DSWE class 4 (water or wetland-low confidence) includes mixed vegetation and water areas, which compositionally aligns it with classes 2 and 3, its dynamics are frequently at variance with those of the other water classes. Class 4 fluctuates substantially more than the other classes over the study period and regularly represents the most abundant water class. While all four classes register above-average extents in certain months (e.g., October 2013), class 4 is the sole category with these extremes at other times (e.g., January 1993, January 1996). During the wet season, class 4 periodically exceeds $20,000 \mathrm{~km}^{2}$ in surface water area (Figure 4). All classes follow a similar pattern over the course 
of the year: increasing throughout the wet season, peaking in October or November, and receding consistently until reaching a yearly low in April or May.

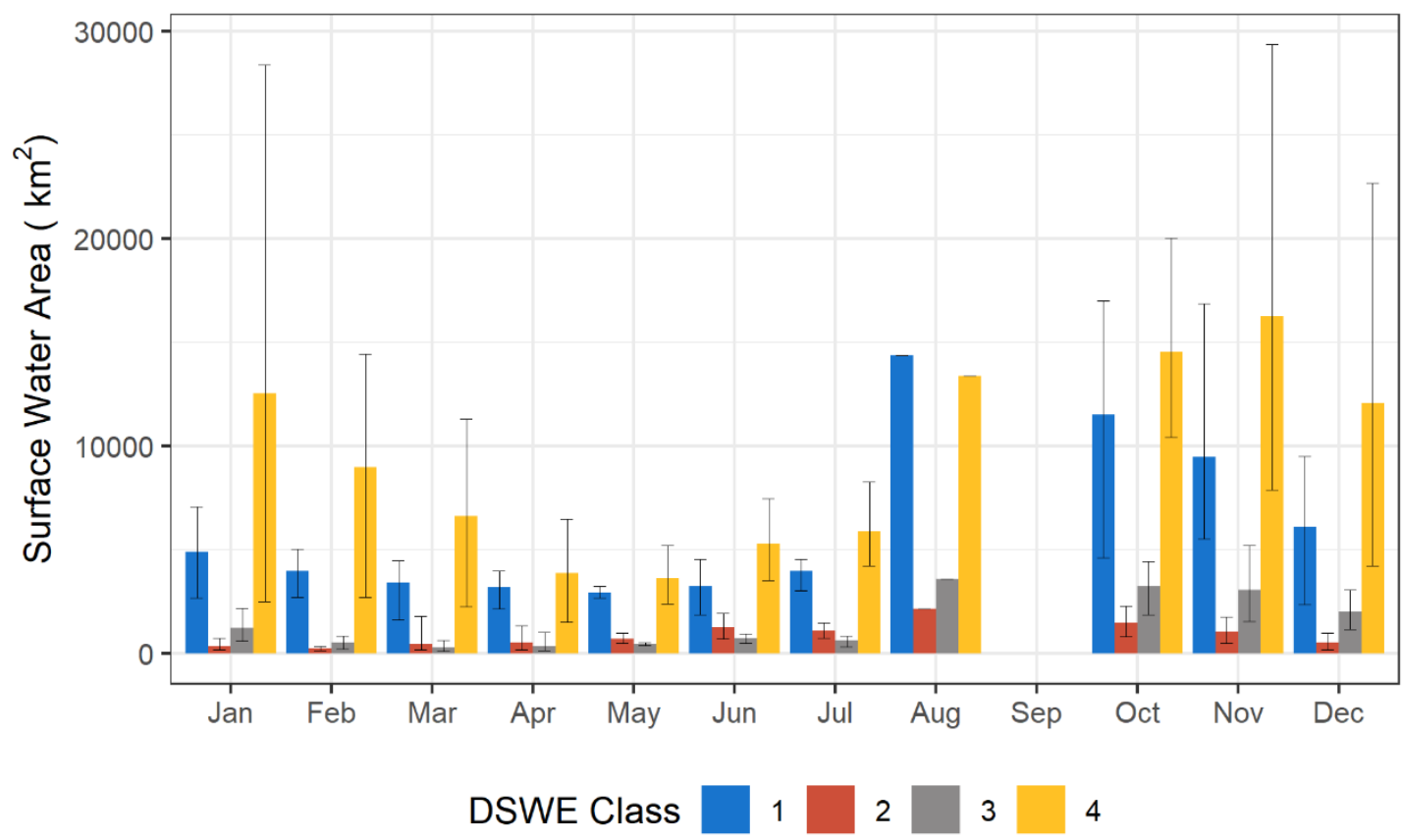

Figure 3. Monthly mean surface water area (1988-2018) across Cambodia in each of the DSWE water classes: (1) high confidence, (2) moderate confidence, (3) partial or vegetated class, and (4) water or wetland-low confidence. Whiskers denote minimum and maximum extents. There was a single clear scene $(<20 \%$ cloud cover over the entire country) in August across the time period; there were no clear scenes in September.

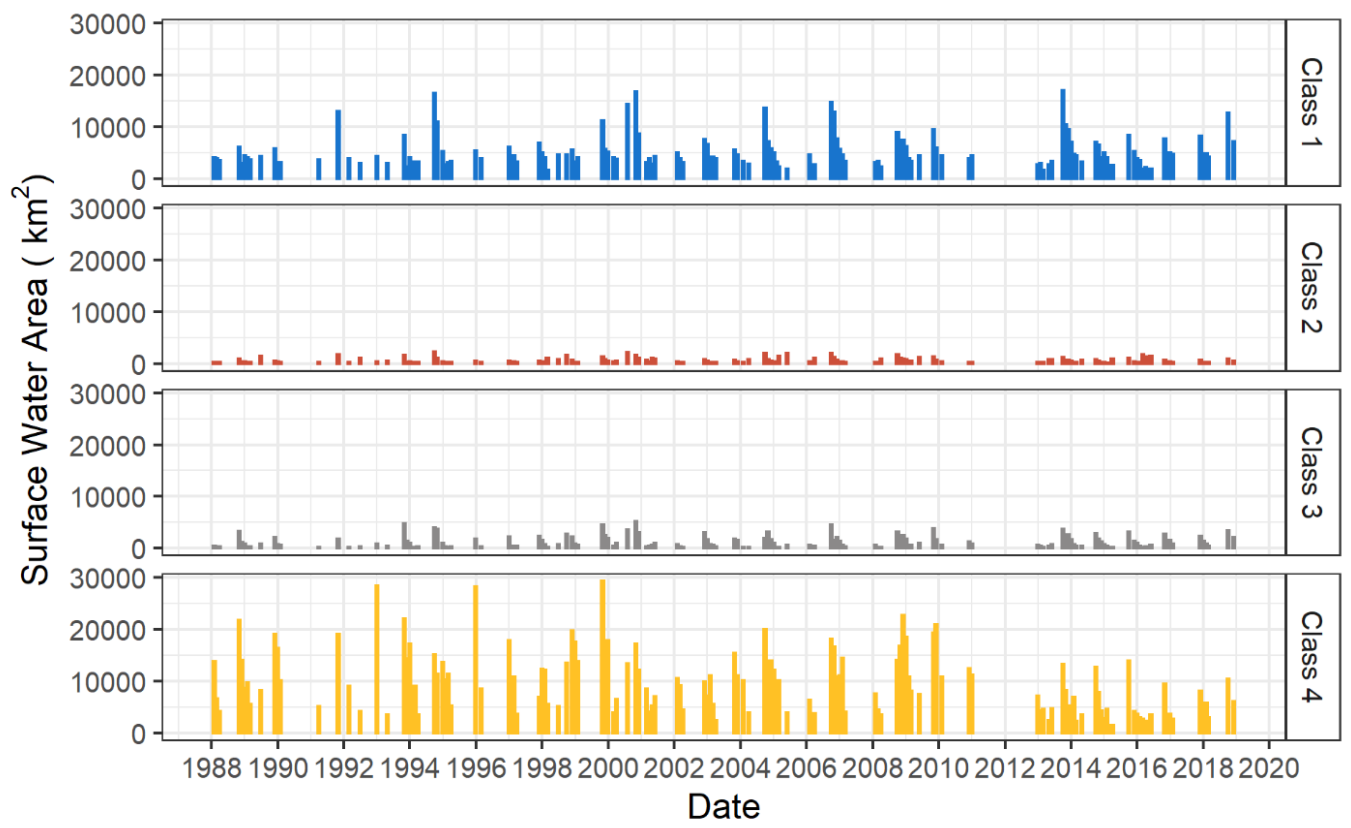

Figure 4. Surface water area by DSWE water class for Cambodia, plotted for each month that had $>80 \%$ Landsat coverage and $<20 \%$ clouds. DSWE water classes are as follows: Class 1 -high confidence water, class 2 - moderate confidence water, class 3-partial or vegetated class, and class 4 -water or wetland-low confidence. 
As expected, the highest concentration of classes 2, 3, and 4 is located in parts of Cambodia characterized by seasonal lakes and wetlands. The visual inspection of these locations on the DSWE maps shows that lower-confidence classes often speckle the periphery of clear water areas and appear to be partially inundated vegetation, consistent with class definitions (Figure 5). In other locations, these classes appear to represent vegetation with no water visible.
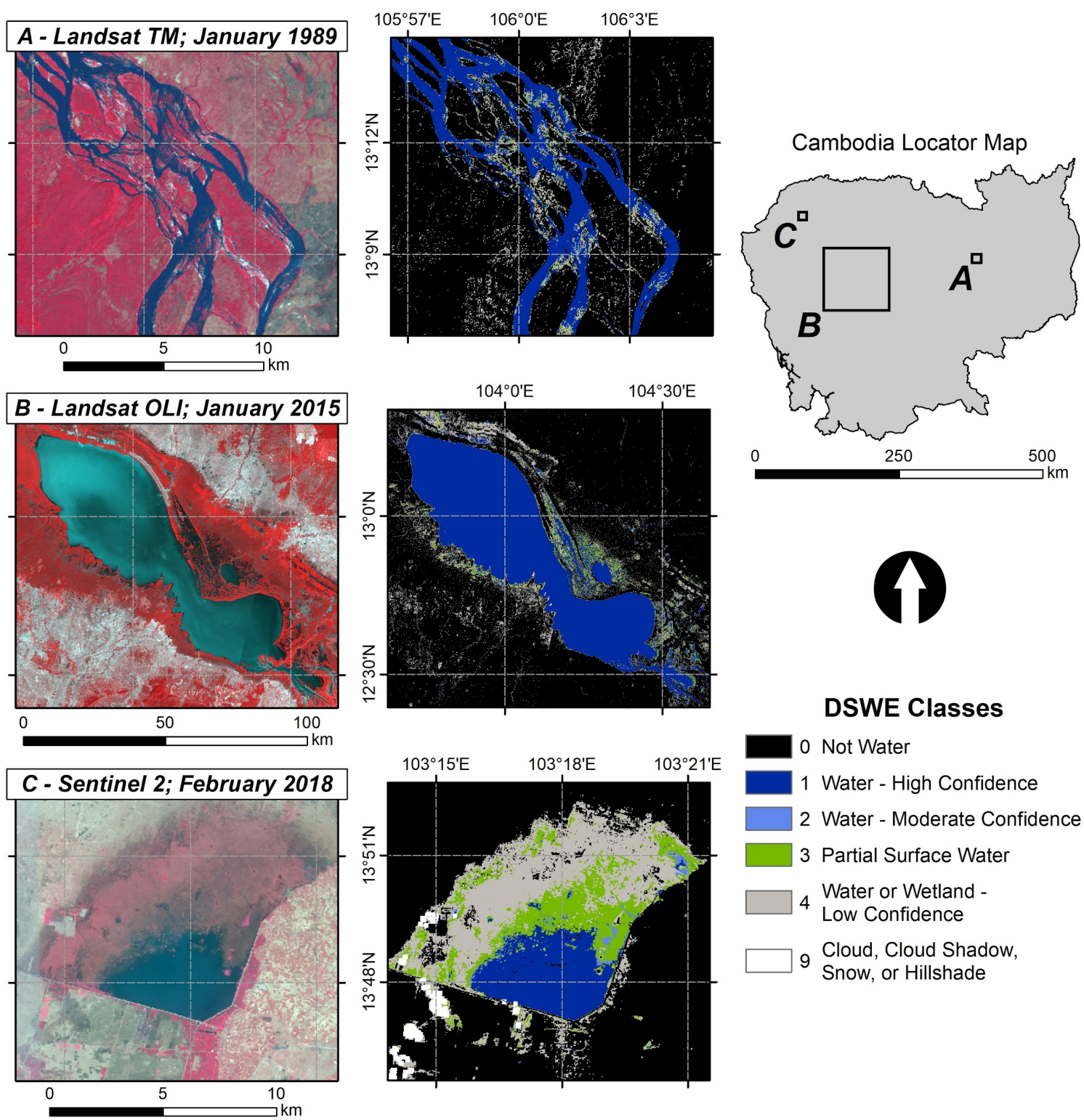

\section{DSWE Classes}

\section{Not Water}

1 Water - High Confidence

2 Water-Moderate Confidence

3 Partial Surface Water

4 Water or Wetland -

Low Confidence

Cloud, Cloud Shadow

Snow, or Hillshade

Figure 5. Examples of satellite imagery collected over Cambodia and corresponding DSWE maps. (Left) Landsat and Sentinel-2 images are represented as false color composites (NIR-R-G). (Right) Corresponding areas are categorized into DSWE classes.

A comparison of vegetation greenness between moderate-to-low confidence water pixels and high-confidence water pixels can be performed by summarizing the range of select vegetation index values for each class. In two separate years, we consistently find that NDVI increases its movement from higher-to-lower water confidence classes (Figure 6). These measures of vegetation greenness, in conjunction with qualitative observations, explain that lower-confidence pixels are more vegetated and less wet than "high confidence" water pixels that largely capture clear or open water areas. In addition to having more vegetation, pixels classified as "wetland-low confidence" also have higher slope values in 1989 and 2015 than the other DSWE classes. This difference is more pronounced in 
1989. The average slope for class 4 is also higher is 1989 compared to 2015, which may be in part due to the much larger amount of class 4 pixels mapped in 1989, where water levels were higher overall (i.e., approximately 300\% more class 4 pixels) and extended into locations not mapped as inundated in 2015.
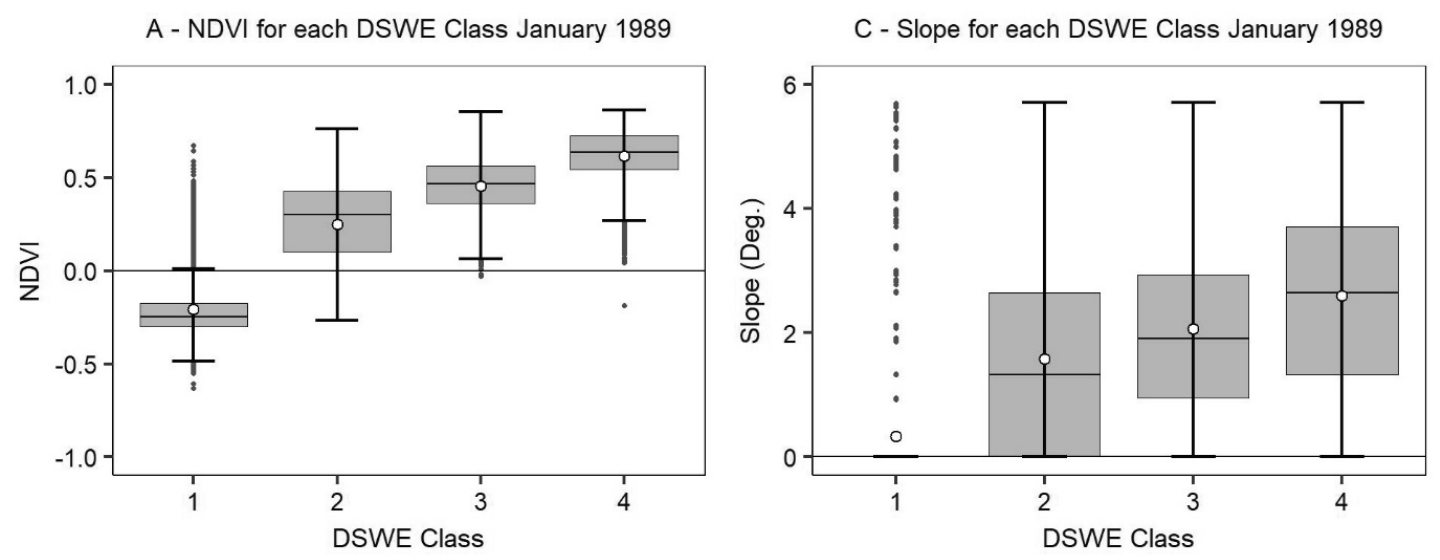

B - NDVI for each DSWE Class January 2015
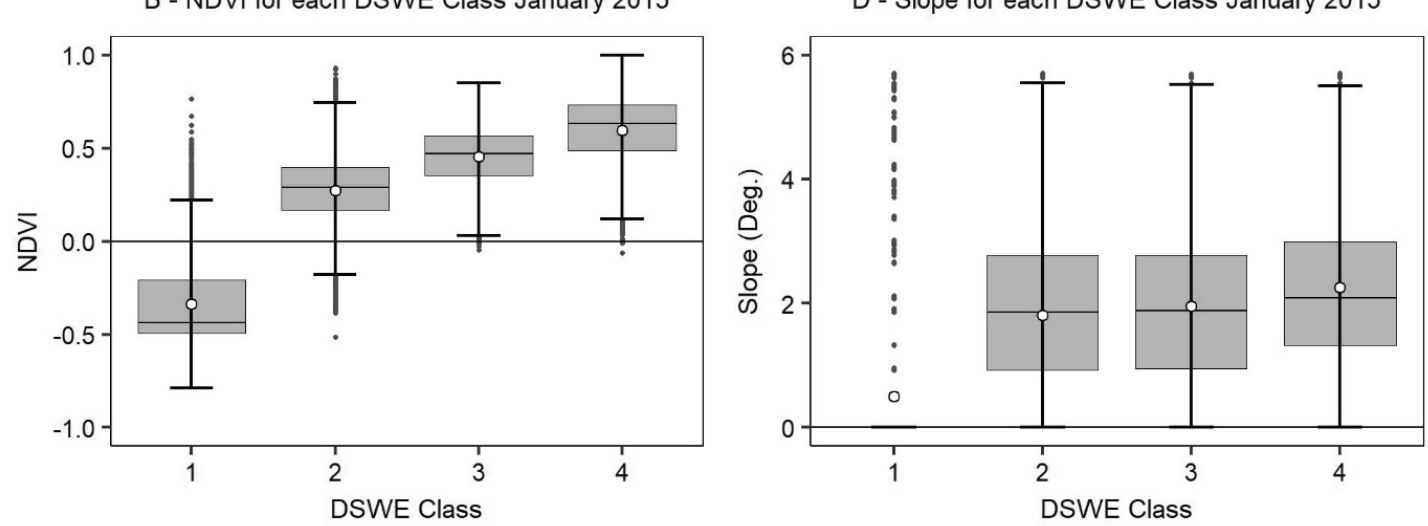

Figure 6. Boxplots of Normalized Difference Vegetation Index (NDVI) values summarized for all DSWE water pixels across Cambodia in January 1989 (A) and January 2015 (B). Boxplots of slope values derived from Shuttle Radar Topography Mission digital elevation data are also summarized for all DSWE water pixels across Cambodia in January 1989 (C) and January 2015 (D). Consolidated DSWE classes are 1 (high-confidence water), 2 (moderate-confidence water), 3 (potential wetland), and 4 (low-confidence water). The black horizontal line in each boxplot represents the median NDVI, the lower and upper box edges represent the first and third quartiles, respectively, and the whiskers represent the data minimum and maximum. The white circle in each plot is the mean for that class.

\subsection{Comparing DSWE to JRC Maps}

A comparison between "high-confidence" water in DSWE (DSWE class 1) and the water class in JRC (JRC class 2) using data that meet our Landsat coverage and clear-sky requirements results in a correlation of $\mathrm{r}=0.78$ ( $\mathrm{p}$-value $<0.001$ ) for 117 months of overlapping data spanning the study period (1988-2018) (Figure 7). Although the independent estimates of water extent appear to coincide well in terms of capturing the overall inundation dynamics, key differences exist on certain dates. The most notable discrepancy between DSWE and JRC monthly products is during the wet seasons in 2000 and 2014. We investigated the underlying data but were not able to make a definitive assessment to account for the differences. In November 2000, DSWE and JRC measured 16,900 km² and $6500 \mathrm{~km}^{2}$ of the inundation area, respectively; in October 2014, the extents are $7100 \mathrm{~km}^{2}$ and 12,200 $\mathrm{km}^{2}$. Within the WWF swamp ecoregions, the Pearson correlation between the DSWE "high-confidence" water class and the JRC "water presence" class was 0.82 (p-value $<0.001$ ). In these ecoregions, JRC area estimates are typically $130 \mathrm{~km}^{2}$ higher than DSWE estimates in any given month. The comparison between products at the ecoregion scale yields similar patterns to those at the country scale; i.e., the 
dynamics are broadly comparable in timing and magnitude, but sporadic discrepancies exist. The primary difference is that absolute values are about $20 \%$ lower due to the smaller area of analysis.

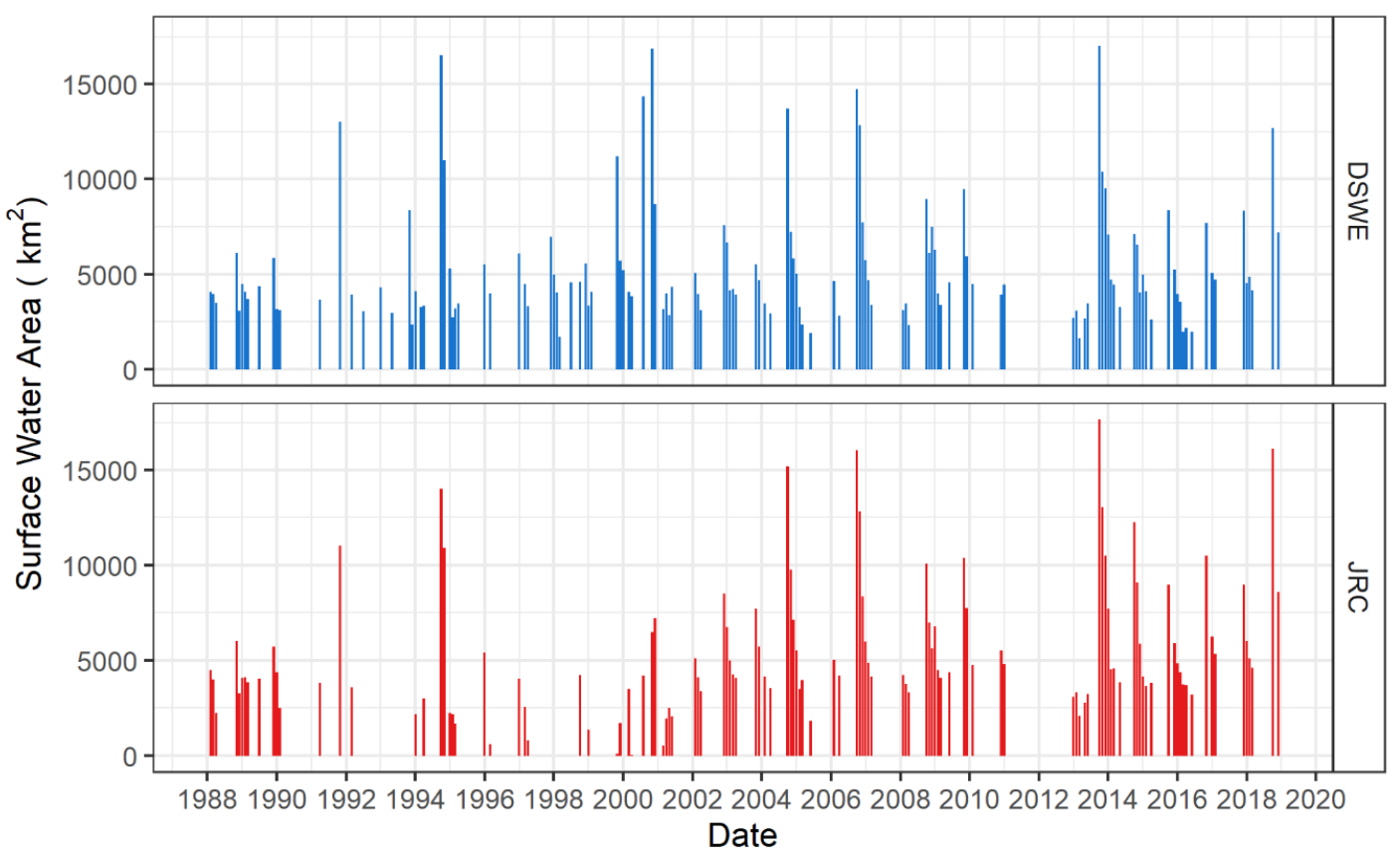

Figure 7. Monthly surface area estimates of DSWE Class 1-'high-confidence' water (top) - and JRC Class 2-'water presence' class (bottom) -for all of Cambodia, 1988-2018. The time series consists of months in which DSWE composites met minimum clear-sky and Landsat data coverage requirements. JRC data were not produced in 14 months; in 8 additional months, JRC's total surface water area was $<1000 \mathrm{~km}^{2}$.

Other notable discrepancies arise during gaps in the availability of data for either the DSWE or JRC product. As noted earlier, missing imagery and excessive cloud obstruction led the exclusion of 241 months from the DSWE time series. JRC data were not produced in 50 months over the study period and had more than $80 \%$ "no data" in 44 additional months. Missing data and low area estimates are particularly noticeable from 1991 through 1999 (Figure 7). Given that JRC is derived from the same time series of Landsat imagery as DSWE, the datasets are subject to similar periods of missing data. Both sets of maps visually correspond well to water presence across the landscape when classified maps exist.

\subsection{Multi-Date Accuracy Assessment}

Error matrices for the 1989, 2015, and 2018 DSWE surface water maps are reported in Table 2 for manual interpretations of reference points in false-color (NIR-R-G) 1989 and 2015 Landsat 30-m image mosaics and a 2018 Sentinel-2 10-m image composite. High overall surface water mapping accuracy ( $>85 \%)$ was documented for all three study dates. Omission error (100\% minus producer's accuracy) rates of $13.4 \%, 15.9 \%$, and $12.4 \%$ for low/no water in 1989, 2015, and 2018 were much higher than the commission error (100\% minus user's accuracy) rates of $2.2 \%, 0 \%$, and $0 \%$, respectively, suggesting that low-water areas were commonly omitted by the model. Conversely, omission error rates of $6.5 \%$, $2.8 \%$, and 5.7\% for "high confidence" water in 1989, 2015, and 2018 were lower than the commission error rates of $19.4 \%, 20.4 \%$, and $8.3 \%$, respectively. DSWE consistently classified points interpreted as "moderate confidence" water as "low confidence" water pixels, contributing to $<8 \%$ producer's and user's accuracy for the "moderate confidence" water class in all three years. User's accuracy was only marginally better for "moderate confidence" water. These poor-performing areas led to Kappa values lower than the overall accuracy. In general, the GEE DSWE model had high accuracy and performed 
well in mapping the presence and absence of low and high-confidence surface water. However, the model did a poor job discerning between low-confidence and partial water classes.

Table 2. Confusion matrices for 1989 (A), 2015 (B), and 2018 (C).

(A)

\begin{tabular}{ccccc}
\hline \multirow{2}{*}{1989 Confusion Matrix } & \multicolumn{3}{c}{ 1989 Landsat-Interpreted Reference } \\
\cline { 2 - 5 } & & Low/No Water (0 and 4) & Moderate Water (2 and 3) & High Water (1) \\
\hline \multirow{3}{*}{ DSWE Classes } & Low/No Water (0 and 4) & 226 & 28 & 7 \\
\cline { 2 - 5 } & Moderate Water (2 and 3) & 3 & 2 & 0 \\
\cline { 2 - 5 } & High Water (1) & 2 & 0 & 29 \\
\hline \multicolumn{2}{c}{ Overall Accuracy $=86.5 \% ;$ Kappa $=55.4 \%$} &
\end{tabular}

(B)

\begin{tabular}{|c|c|c|c|c|}
\hline \multirow{2}{*}{\multicolumn{2}{|c|}{2015 Confusion Matrix }} & \multicolumn{3}{|c|}{2015 Landsat-Interpreted Reference } \\
\hline & & Low/No Water (0 and 4) & Moderate Water (2 and 3) & High Water (1) \\
\hline \multirow{3}{*}{ DSWE Classes } & Low/No Water (0 and 4) & 211 & 34 & 6 \\
\hline & Moderate Water (2 and 3) & 0 & 3 & 3 \\
\hline & High Water (1) & 0 & 1 & 35 \\
\hline
\end{tabular}

$(C)$

\begin{tabular}{lccccc}
\hline \multirow{2}{*}{2018 Confusion Matrix } & \multicolumn{3}{c}{ 2018 Sentinel-2-Interpreted Reference } \\
\cline { 2 - 5 } & & Low/No Water (0 and 4) & Moderate Water (2 and 3) & High Water (1) \\
\hline \multirow{2}{*}{ DSWE Classes } & Low/No Water (0 and 4) & 184 & 24 & 2 \\
\cline { 2 - 5 } & Moderate Water (2 and 3) & 0 & 2 & 2 \\
\cline { 2 - 5 } & High Water (1) & 0 & 2 & 33 \\
\hline
\end{tabular}

Overall Accuracy $=88.3 \%$; Kappa $=66.6 \%$

\subsection{Annual and Monthly Summary of the "High Confidence" Water Class}

Olofsson et al. [45] suggest the estimation of area based on a sample of reference data rather than relying on pixel counts alone, because the latter do not account for classification uncertainty. For this reason, we only provide a general assessment of surface water area and observations about higher and lower water years. The summation of pixels classified as "high confidence" (class 1) suggests that, on average, roughly $5400 \mathrm{~km}^{2}$ of land in Cambodia is inundated over the course of any given year (i.e., annual surface water extent). In the past 31 years, the six years marked by higher than average surface water were 1991, 1994, 2000, 2006, 2013, and 2018. Levels were 64\% and 59\% higher than average in 2000 and 2006, respectively. Conversely, 1990, 1992, and 2005 were the three years where water levels were lowest over the observed period. In each of these years, the average surface water extent was $<3500 \mathrm{~km}^{2}(<65 \%$ of average) (Figure 8 ).

Monthly summaries of the "high confidence" water class provide much more detail on seasonal water fluctuations. The temporal richness of the monthly data in certain years allows the observation that surface water area may vary substantially between wet and dry seasons. For example, in the data-rich year 2003, there is a relatively small difference between the annual (dry-season) minimum $\left(3900 \mathrm{~km}^{2}\right)$ and the annual (wet-season) maximum $\left(6600 \mathrm{~km}^{2}\right)$ water area. On the other hand, 2013 shows a much larger difference between water levels over the year, varying from $1600 \mathrm{~km}^{2}$ in March 2013 to 17,000 km² in October 2013. In many cases, these differences can be explained using historical monthly National Center for Atmospheric Research (NCAR) precipitation data summarized at the country scale. Precipitation data were accessed through the Climate Change Knowledge Portal (CCKP). Peaks in surface water typically coincide with wet season precipitation or total precipitation in the same calendar year. Climate records show below-average wet-season precipitation in 1993, 1997, 2005, 
2008, and 2015, and low annual precipitation in 1996, 2005, and 2007. The same records show heavy wet-season rainfall totals in 1988, 1994, 2000, 2006, 2007, and 2011, and high annual rainfall in 2001, 2006, 2009, and 2013. Peaks in wet-season surface water and rainfall align well in 1994, 2006, 2009, and 2013 but are divergent in magnitude or direction in 1991, 2000, and 2011 (Figure 8). Despite some correspondence in years of heavy rainfall, Pearson correlations between monthly precipitation averages and class 1 water area (for clear, low-cloud months) at the country-scale remain low $(r=0.37)$. Correlations improve only slightly $(r=0.41)$ if classes 1,2 , and 3 are considered, but decrease when class 4 is added $(r=0.18)$.

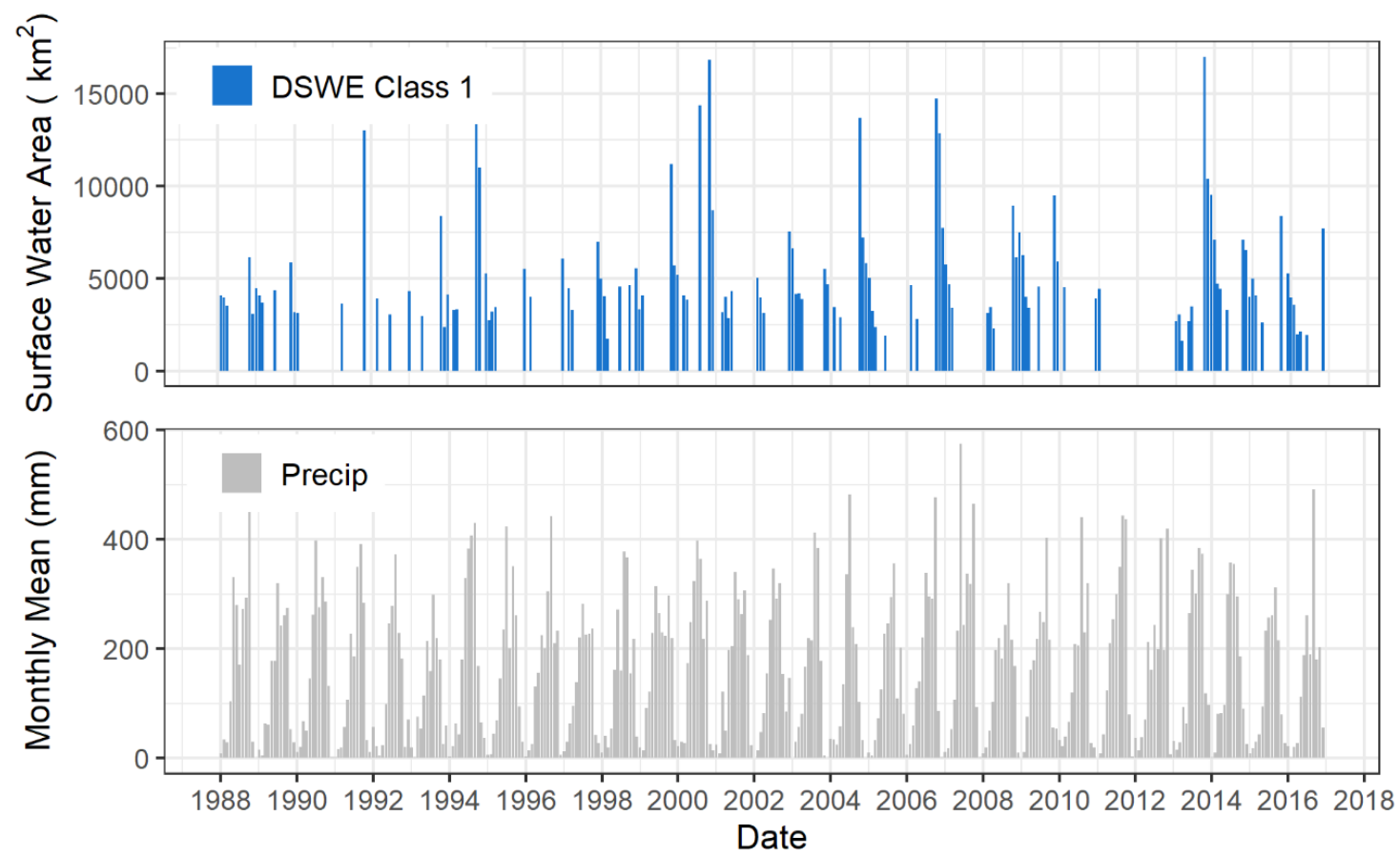

Figure 8. Monthly surface water area (top) and corresponding monthly average precipitation (bottom) for Cambodia, 1988-2018. Data are derived from historical monthly National Center for Atmospheric Research precipitation records and DSWE Class 1 ("high confidence water") totals.

\section{Discussion}

In this work, we demonstrated the applicability of DSWE for generating monthly and annual time series of surface water inundation maps in an area outside the continental United States. As with any project reliant on optical satellite imagery, the frequency of clear images of inundation extent was largely determined by the availability of cloud-free acquisitions. Cambodia is a difficult region over which to assemble a temporally dense time series of Landsat data because of the extensive seasonal cloud cover. Of the 372 monthly composite outputs for Cambodia between 1985 and 2018, nearly 40\% $(n=148)$ had more than $20 \%$ "no data" due to clouds or cloud shadow. The high proportion of surface area obscured by cloud cover is compounded by the inconsistent record of historical Landsat imagery. Landsat acquisition over Cambodia has been remarkably erratic; $41 \%$ of the monthly composites $(n=151)$ had more than $20 \%$ "no data" due to missing scenes. Landsat data were completely inaccessible in Cambodia for 15 months during 1988 to 2018 due to international collection issues, which have occurred to varying degrees in other countries as well $[28,46]$. The occurrence of cloud cover and data gaps overlapped at numerous times, leaving 131 discrete months-an average of 4 months of usable data per year-for subsequent analyses. No composite scenes met our data quality thresholds for September in any year, and only one such scene existed for August. 


\subsection{Discontinuity of the Landsat Record}

The combination of cloud cover and missing data precludes the assembly of a full and consistent record of hydrologic dynamics in Cambodia from Landsat imagery alone. The dearth of imagery in the wet season, in particular, limits insights into flood dynamics and how surface water extents change as a function of precipitation. Despite these limitations, some applications may still find benefits in the 241 months of partially missing or obscured data excluded during our compilation of summary statistics. Our imposition of quality limits on a country-wide scale leaves open the possibility that cloud cover and/or missing data were more prevalent in some areas than others. An avenue of future research would be to examine the spatial distribution of "no data" pixels throughout the study interval and focus on areas with higher consistency of valid data. Assemblies of clear imagery over constrained local or regional extents could nonetheless contribute valuable information about hydrologic changes over time. Alternatively, applications in which broad spatial coverage is more important than the detection of high-frequency fluctuations may benefit from annual DSWE maximum water extent maps to produce generalized estimates of surface water changes with fewer data dropouts.

Although the overall proportions of cloudy imagery and missing data are relatively high, they are a function of external circumstances rather than an inherent limitation of the DSWE model. Our examination of DSWE applicability to this area of the globe returned positive results. The comparison of the DSWE "high confidence" water class to an independent estimate of landscape water extents (JRC) supports the viability of DSWE use. The number of "high confidence" (i.e., open-water) pixels identified in DSWE monthly maps correlates well spatially and temporally with JRC estimates of water presence. Both products are subject to similar periods of missing data but map open water areas satisfactorily when cloud-free imagery are available. The binary JRC maps are more generalized than DSWE maps given their lack of water presence gradations.

\subsection{Accuracy Assessment}

The assessment of all DSWE water classes relative to independent reference images at Landsat resolution or higher (i.e., Sentinel-2) provides additional insights into the reliability of DSWE in this geographic context. The DSWE model had high overall accuracy ( $>85 \%)$ across the three dates of assessment, but performed better in mapping the occurrence of "low confidence" (e.g., the combination of class 0 -no water and class 4-low-confidence water) and "high confidence" (e.g., class 1-open water) surface water classes compared to partial or mixed vegetation water classes (i.e., classes 2 and 3). The "high confidence" class had large commission errors in 1989 and 2015, indicating that the DSWE model may be overly sensitive to water presence. Class confusion is highlighted in the comparison of each DSWE class to NDVI in 1989 and 2015 as summarized across Cambodia. This analysis illustrates that possible wetland and moderate-confidence pixels consistently included vegetation, as expected. The combination of water and vegetation also contributed to some spectral overlap between classes 2, 3, and 4. Overlapping NDVI ranges by class occur in both 1989 and 2015. Diagnostic tests also suggest that "wetland-low confidence" pixels have higher slopes and more vegetation that other DSWE classes. The higher slopes that represent class 4 pixels relative to those in other classes may simply confirm that water may run off even at subtle slopes, leading to less water pooling and, as a result, lower inundation.

Moderate-to-low-confidence DSWE classes represent partial water coverage and hold tremendous potential for shedding light into wetland dynamics. However, the consistent assignment of pixels comprising water and vegetation into discrete classes is problematic. Collectively, the mixed pixel categories (classes 2, 3, and 4) had higher classification errors than class 1. Subtle variations in the amount of water inundation likely contributed to shifts between these classes; other potential contributing factors are alterations in water turbidity and vegetation condition from month to month. Despite class confusion and higher error rates for mixed water/vegetation pixels, we do not conclude that DSWE should only be applied to detect water presence (i.e., the "high confidence" class 1) and absence. A qualitative assessment confirms that these vegetation/water classes capture much of the 
intermittent, seasonal inundation within the floodplain, but class 4 clearly includes errors; it maps unrealistically high numbers of pixels on certain dates and demonstrates temporal variability to a degree that is physically improbable. These spatio-temporal characteristics, along with the fact that class 4 was often difficult to separate from vegetation both visually or spectrally (NDVI), collectively suggest that these pixels should be used with caution to represent surface water since they reside on the margin of water and vegetation.

An advantage of the DSWE algorithm is that it is fully and publicly documented; the applicable code can be readily replicated and customized on a user's desired processing platform. Furthermore, the algorithm can be applied to other geographic areas because it does not involve complicated, site-specific model training requirements. The adaptation of the DSWE model in Google Earth Engine is straightforward given the existence of digital elevation datasets in the GEE public-access catalog that have near-global or global coverage. Shuttle Radar Topography Mission data encompass most land surfaces between $60^{\circ} \mathrm{N}$ and $54^{\circ} \mathrm{S}$ [40] and are a reasonable substitute for the higher-resolution DEMs available in the United States. The transferability of the DSWE algorithm differs from the JRC mapping process, which may be difficult to replicate due to the proprietary nature of the underlying methods. The existence of an alternate method of producing national-to-global-scale surface water maps allows users to compare independent derivations of inundation products, choose the most applicable product for their needs, and harmonize efforts to identify where products exhibit geospatial agreement before using the data in a wide array of applications.

\subsection{Future Directions}

Perhaps the most promising area for future exploration is establishing how surface water changes as a function of precipitation and other possible explanatory variables (e.g., soils, impervious surfaces, etc.). The comparison of monthly surface water maps to monthly precipitation records over the observation period suggests that surface water peaks lag slightly behind precipitation peaks. This general observation could be refined by linking inundation dynamics to specific climatic and ecohydrological forcing mechanisms, which can exert varying degrees of influence over time and space. A Landsat-based effort set in an extensive Australian river system concluded that the primary drivers of floodplain and non-floodplain surface water dynamics were river flow and precipitation, respectively [47]. The amount of pre-flooding soil moisture can also affect the extent and duration of subsequent inundation events [48].

Annual maps may prove to be a better resource to investigate coincident trends between surface water totals with rainfall years by providing a more complete record, but intra-year dynamics are lost in the temporal aggregation process. Retaining the temporal richness of the monthly time steps may require innovative approaches to fill gaps. One way to improve the temporal alignment of mapped surface water extents with weather station records is to incorporate additional images (e.g., MODIS or Sentinel-2) into the DSWE mapping process to supplement and extend the Landsat-derived time series. This multi-sensor approach may hold the potential to capture a cloud-free landscape more frequently and create a stronger linkage to discrete weather events.

A variety of other use cases may also benefit from DSWE maps generated for Cambodia and elsewhere across the globe. Researchers interested in simulating flood events can rely on inundation maps as direct empirical inputs to help calibrate their models. Comparisons of inundation classes against NDVI and slope may also provide added insights in the model refinement process by summarizing how vegetated and steep water areas may be. These characteristics likely vary based on the geographic scope of analysis. This sort of knowledge may help generate geographically specific metrics that can be used to customize models based on regional characteristics.

A multi-decadal record of past flood events can be used to better characterize floodwater characteristics and to help assess human and economic vulnerabilities to flooding. The aggregation of topographic information such as slope by water classes may inform the extraction of floodwater depth patterns. Studies have explored the potential of creating maps of water depth by combining DEMs 
with maps of surface water extent derived from various sources: Envisat and RADARSAT-1 microwave imagery [49], MODIS and Sentinel-1 microwave imagery [50], and modeled data [51]. Cohen et al. [50] reported that using a 30-m DEM in low-relief areas led to better results than a higher-resolution DEM, which means a combination of DSWE and Shuttle Radar Topography Mission data may be well-suited for floodwater depth mapping in Cambodia. Past mapped events or calibrated model outputs can also serve as direct inputs to community vulnerability assessments by overlaying maps of agricultural and development lands. Areas of overlap may represent communities and economic activities at risk, which in turn can be used to prioritize mitigation actions [52].

\section{Conclusions}

Time-series of accurate surface water maps can provide critical insights into the timing and localized consequences of weather extremes. These maps are particularly valuable in the many flood-prone countries that lack extensive stream gage networks for tracking hydrologic dynamics. Models such as DSWE can bridge the data gap by translating the raw spectral information of satellite data into classifications of water presence. This investigation into applying the DSWE model beyond the United States using the Google Earth Engine cloud computing platform has had a positive outcome in that the model successfully classified imagery; however, the completeness of the time series largely depends on the availability of cloud-free imagery. The DSWE model shares the same set of limitations that hamper all surface water detection efforts using Landsat and other optical imagery platforms. Despite losing nearly 65\% of the time series to these issues (131 of 372 months met our screening requirements), the remaining data performed well in each of our tests. Monthly, multi-class GEE outputs were evaluated against existing monthly surface water maps. Annual maps were also compared to NDVI to better understand the amount of vegetation greenness in each water class, and independently assessed for accuracy at multiple years in the time series.

Results suggest that the DSWE maps correlate well to JRC data $(r=0.78, \mathrm{p}$-value $<0.001)$ at the country scale and can occasionally generate data during gaps in the JRC time series. The comparison of DSWE classes to NDVI and slope suggests that class gradations from high-to-low confidence water coincide with increasing vegetation and slope, with class 4-low-confidence-water pixels representing higher amounts of vegetation, steeper slopes, and low amounts of surface water in some locations. While partially inundated vegetation classes should be used with caution, we find that the multiple DSWE classes allow insight into the nuanced character of surface water inundation. Perhaps the most important finding in this study is that the DSWE model creates accurate surface water maps in three separate tests $(>85 \%)$. In conclusion, the map resources generated by this study provide monthly-to-annual snapshots of surface water that can be assembled into dense time series and compared to precipitation records to begin to understand the causes of surface water change. Causal analyses typically require a larger regional context and a broader set of explanatory variables. Future research focusing on quantifying the connection between precipitation and surface water changes holds great potential for identifying how the location and amount of rainfall may contribute to flooding.

The DSWE model holds great potential as a tool in future applications that aim to improve the temporal resolution of surface water mapping or ascertain factors that contribute to inundation events. The most immediate benefit of this research lies in demonstrating the applicability of the DSWE algorithm beyond US boundaries. The relevant GEE code is made available as a USGS Data Release [53] created as a complement to this article. With a few small changes to the code, this cloud-based method can be transferred to produce multi-class DSWE maps anywhere across the globe.

Supplementary Materials: A USGS data release including the data and code used for this research can be found on USGS ScienceBase (https://doi.org/10.5066/P9LH9YYF). The 16 TIF raster data files are classified surface water maps created using the Dynamic Surface Water Extent (DSWE) model implemented in Google Earth Engine across Landsat 30-m imagery collected from January 1988 through December 2018. The Google Earth Engine code is also included as part of the data release. 
Author Contributions: Conceptualization C.E.S. and J.J.W.; Methodology C.E.S. and J.J.W.; formal analysis, C.E.S. and R.E.P.; writing - original draft preparation, C.E.S.; writing—review and editing, C.E.S., J.J.W., and R.E.P.; visualization, C.E.S, R.E.P., and J.J.W. All authors have read and agreed to the published version of the manuscript.

Funding: Funding for this work was provided by the U.S. Geological Survey Climate Research and Development and Land Change Science Programs of the Land Resources Mission Area.

Acknowledgments: We would like to thank Adam Oliphant of the USGS and five anonymous reviewers for their constructive reviews of the manuscript. Any use of trade, firm, or product names is for descriptive purposes only and does not imply endorsement by the U.S. Government.

Conflicts of Interest: The authors declare no conflict of interest.

\section{References}

1. Borga, M.; Gaume, E.; Creutin, J.D.; Marchi, L. Surveying flash floods: Gauging the ungauged extremes. Hydrol. Process. 2008, 22, 3883-3885. [CrossRef]

2. Lettenmaier, D.P. Observations of the Global Water Cycle-Global Monitoring Networks. In Encyclopedia of Hydrological Sciences; Anderson, M.G., McDonnell, J.J., Eds.; John Wiley \& Sons, Ltd.: Chichester, UK, 2005.

3. Moore, R.J.; Cole, S.J.; Bell, V.A.; Jones, D.A. Issues in flood forecasting: Ungauged basins, extreme floods and uncertainty. IAHS Publ. Ser. Proc. Rep. 2006, 305, 103-122.

4. Carter, R.W.; Davidian, J. General Procedure for Gaging Streams, US Geological Survey. 1968. Available online: https://pubs.usgs.gov/twri/twri3-A6/ (accessed on 2 March 2020).

5. Bales, J.D.; Wagner, C.R. Sources of uncertainty in flood inundation maps. J. Flood Risk Manag. 2009, 2, 139-147. [CrossRef]

6. Beesley, L.; King, A.J.; Amtstaetter, F.; Koehn, J.D.; Gawne, B.; Price, A.; Nielsen, D.L.; Vilizzi, L.; Meredith, S.N. Does flooding affect spatiotemporal variation of fish assemblages in temperate floodplain wetlands? Freshw. Biol. 2012, 57, 2230-2246. [CrossRef]

7. Brock, M.A.; Nielsen, D.L.; Shiel, R.J.; Green, J.D.; Langley, J.D. Drought and aquatic community resilience: The role of eggs and seeds in sediments of temporary wetlands. Freshw. Biol. 2003, 48, 1207-1218. [CrossRef]

8. Petty, T.R.; Noman, N.; Ding, D.; Gongwer, J.B. Flood Forecasting GIS Water-Flow Visualization Enhancement (WaVE): A Case Study. J. Geogr. Inf. Syst. 2016, 8, 692-728. [CrossRef]

9. Zhang, F.; Zhu, X.; Liu, D. Blending MODIS and Landsat images for urban flood mapping. Int. J. Remote Sens. 2014, 35, 3237-3253. [CrossRef]

10. Lebel, L.; Sinh, B.T. Risk Reduction or Redistribution? Flood Management in the Mekong Region. Asian J. Environ. Dis. Manag. 2009, 1, 25. [CrossRef]

11. Alsdorf, D.E.; Rodríguez, E.; Lettenmaier, D.P. Measuring surface water from space. Rev. Geophys. $2007,45$. [CrossRef]

12. Sakamoto, T.; Van Nguyen, N.; Kotera, A.; Ohno, H.; Ishitsuka, N.; Yokozawa, M. Detecting temporal changes in the extent of annual flooding within the Cambodia and the Vietnamese Mekong Delta from MODIS time-series imagery. Remote Sens. Environ. 2007, 109, 295-313. [CrossRef]

13. Sanyal, J.; Lu, X.X. Application of Remote Sensing in Flood Management with Special Reference to Monsoon Asia: A Review. Nat. Hazards 2004, 33, 283-301. [CrossRef]

14. Brakenridge, R.G.; Cohen, S.; Kettner, A.J.; De Groeve, T.; Nghiem, S.V.; Syvitski, J.P.M.; Fekete, B.M. Calibration of satellite measurements of river discharge using a global hydrology model. J. Hydrol. 2012, 475, 123-136. [CrossRef]

15. Van Dijk, A.I.; Brakenridge, G.R.; Kettner, A.J.; Beck, H.E.; De Groeve, T.; Schellekens, J. River gauging at global scale using optical and passive microwave remote sensing: Satellite-based river gauging at global scale. Water Resour. Res. 2016, 52, 6404-6418. [CrossRef]

16. Schumann, G.; Brakenridge, G.; Kettner, A.; Kashif, R.; Niebuhr, E. Assisting Flood Disaster Response with Earth Observation Data and Products: A Critical Assessment. Remote Sens. 2018, 10, 1230. [CrossRef]

17. Lakshmi, V. Remote Sensing of Hydrological Extremes; Springer Science + Business Media: New York, NY, USA, 2016.

18. Gorelick, N.; Hancher, M.; Dixon, M.; Ilyushchenko, S.; Thau, D.; Moore, R. Google Earth Engine: Planetary-scale geospatial analysis for everyone. Remote Sens. Environ. 2017, 202, 18-27. [CrossRef] 
19. Pekel, J.-F.; Cottam, A.; Gorelick, N.; Belward, A.S. High-resolution mapping of global surface water and its long-term changes. Nature 2016, 540, 418-422. [CrossRef]

20. Dawson, T.P.; Berry, P.M.; Kampa, E. Climate change impacts on freshwater wetland habitats. J. Nat. Conserv. 2003, 11, 25-30. [CrossRef]

21. Reiter, M.E.; Elliott, N.; Veloz, S.; Jongsomjit, D.; Hickey, C.M.; Merrifield, M.; Reynolds, M.D. Spatio-Temporal Patterns of Open Surface Water in the Central Valley of California 2000-2011: Drought, Land Cover, and Waterbirds. JAWRA 2015, 51, 1722-1738. [CrossRef]

22. Schaffer-Smith, D.; Swenson, J.J.; Barbaree, B.; Reiter, M.E. Three decades of Landsat-derived spring surface water dynamics in an agricultural wetland mosaic; Implications for migratory shorebirds. Remote Sens. Environ. 2017, 193, 180-192. [CrossRef]

23. $\mathrm{Xu}, \mathrm{H}$. Modification of normalised difference water index (NDWI) to enhance open water features in remotely sensed imagery. Int. J. Remote Sens. 2006, 27, 3025-3033. [CrossRef]

24. Zhai, K.; Wu, X.; Qin, Y.; Du, P. Comparison of surface water extraction performances of different classic water indices using OLI and TM imageries in different situations. Geo Spat. Inf. Sci. 2015, 18, 32-42. [CrossRef]

25. Walker, J.J.; Soulard, C.E.; Petrakis, R.E. Integrating stream gage data and Landsat imagery to complete time-series of surface water extents in Central Valley, California. Int. J. Appl. Earth Obs. Geoinf. 2020, 84, 101973. [CrossRef]

26. U.S. Geological Survey. Landsat Dynamic Surface Water Extent (DSWE) Algorithm Description Document (ADD) Version 1.0. 2018. Available online: https://prd-wret.s3-us-west-2.amazonaws. com/assets/palladium/production/atoms/files/LSDS-1325-LandsatDynamicSurfaceWaterExtent_

AlgorithmDescriptionDocument-v1.pdf (accessed on 1 April 2018).

27. U.S. Geological Survey. Landsat Dynamic Surface Water Extent (DSWE) Product Guide Version 2.0. 2018. Available online: https://prd-wret.s3-us-west-2.amazonaws.com/assets/palladium/production/s3fs-public/ atoms/files/LSDS-1331-LandsatDynamicSurfaceWaterExtent-DSWE-ProductGuide-v3.0_\%202019_03_19. pdf (accessed on 10 October 2018).

28. Wulder, M.A.; White, J.C.; Loveland, T.R.; Woodcock, C.E.; Belward, A.S.; Cohen, W.B.; Fosnight, E.A.; Shaw, J.; Masek, J.G.; Roy, D.P. The global Landsat archive: Status, consolidation, and direction. Remote Sens. Environ. 2016, 185, 271-283. [CrossRef]

29. Carroll, M.; Loboda, T. Multi-Decadal Surface Water Dynamics in North American Tundra. Remote Sens. 2017, 9, 497. [CrossRef]

30. Tanaka, M.; Sugimura, T.; Tanaka, S.; Tamai, N. Flood-Drought cycle of Tonle Sap and Mekong Delta area observed by DMSP-SSM/I. Int. J. Remote Sens. 2003, 24, 1487-1504. [CrossRef]

31. Davies, G.; McIver, L.; Kim, Y.; Hashizume, M.; Iddings, S.; Chan, V. Water-Borne Diseases and Extreme Weather Events in Cambodia: Review of Impacts and Implications of Climate Change. Int. J. Environ. Res. Public Health 2014, 12, 191-213. [CrossRef]

32. Chea, S.; Sharp, A. Flood Management in Cambodia: Case Studies of Flood in 2009 and 2011. In Proceedings of the International Academy of Engineers (IA-E), Pattaya, Thailand, 24-25 April 2015.

33. Cambodia Disaster Loss and Damage Analysis Report 1996-2013; Cambodia Disaster Loss and Damage Information System. 2014. Available online: https:/www.kh.undp.org/content/dam/cambodia/docs/ EnvEnergy/Cambodia-Disaster-Loss-and-Damage-Analysis-Report\%201996-\%202013.pdf (accessed on 2 March 2020).

34. Torti, J. Floods in Southeast Asia: A health priority. J. Glob. Health 2012, 2, 020304. [CrossRef]

35. Olson, D.M.; Dinerstein, E.; Wikramanayake, E.D.; Burgess, N.D.; Powell, G.V.N.; Underwood, E.C.; D'amico, J.A.; Itoua, I.; Strand, H.E.; Morrison, J.C.; et al. Terrestrial Ecoregions of the World: A New Map of Life on Earth. BioScience 2001, 51, 933. [CrossRef]

36. Soulard, C.; Albano, C.; Villarreal, M.; Walker, J. Continuous 1985-2012 Landsat Monitoring to Assess Fire Effects on Meadows in Yosemite National Park, California. Remote Sens. 2016, 8, 371. [CrossRef]

37. Villarreal, M.; Soulard, C.; Waller, E. Landsat Time Series Assessment of Invasive Annual Grasses Following Energy Development. Remote Sens. 2019, 11, 2553. [CrossRef]

38. Jones, J. Efficient Wetland Surface Water Detection and Monitoring via Landsat: Comparison with in situ Data from the Everglades Depth Estimation Network. Remote Sens. 2015, 7, 12503-12538. [CrossRef]

39. Jones, J. Improved Automated Detection of Subpixel-Scale Inundation-Revised Dynamic Surface Water Extent (DSWE) Partial Surface Water Tests. Remote Sens. 2019, 11, 374. [CrossRef] 
40. Farr, T.G.; Rosen, P.A.; Caro, E.; Crippen, R.; Duren, R.; Hensley, S.; Kobrick, M.; Paller, M.; Rodriguez, E.; Roth, L.; et al. The Shuttle Radar Topography Mission. Rev. Geophys. 2007, 45, RG2004. [CrossRef]

41. Gesch, D.; Oimoen, M.; Greenlee, S.; Nelson, C.; Steuck, M.; Tyler, D. The national elevation dataset. Photogramm. Eng. Remote Sens. 2002, 68, 5-32.

42. Congalton, R.G. A review of assessing the accuracy of classifications of remotely sensed data. Remote Sens. Environ. 1991, 37, 35-46. [CrossRef]

43. Wickham, J.D.; Stehman, S.V.; Gass, L.; Dewitz, J.; Fry, J.A.; Wade, T.G. Accuracy assessment of NLCD 2006 land cover and impervious surface. Remote Sens. Environ. 2013, 130, 294-304. [CrossRef]

44. Story, M.; Congalton, R.G. Accuracy Assessment: A User's Perspective. Photogramm. Eng. Remote Sens. 1986, 52, 397-399.

45. Olofsson, P.; Foody, G.M.; Herold, M.; Stehman, S.V.; Woodcock, C.E.; Wulder, M.A. Good practices for estimating area and assessing accuracy of land change. Remote Sens. Environ. 2014, 148, 42-57. [CrossRef]

46. Goward, S.; Arvidson, T.; Williams, D.; Faundeen, J.; Irons, J.; Franks, S. Historical Record of Landsat Global Coverage: Mission Operations, NSLRSDA, and International Cooperator Stations. Photogramm. Eng. 2006, 72, 1155-1169. [CrossRef]

47. Heimhuber, V.; Tulbure, M.G.; Broich, M. Modeling multidecadal surface water inundation dynamics and key drivers on large river basin scale using multiple time series of Earth-observation and river flow data: Modeling surface water. Water Resour. Res. 2017, 53, 1251-1269. [CrossRef]

48. Westra, T.; De Wulf, R.R. Modelling yearly flooding extent of the Waza-Logone floodplain in northern Cameroon based on MODIS and rainfall data. Int. J. Remote Sens. 2009, 30, 5527-5548. [CrossRef]

49. Schumann, G.; Hostache, R.; Puech, C.; Hoffmann, L.; Matgen, P.; Pappenberger, F.; Pfister, L. High-Resolution 3-D Flood Information From Radar Imagery for Flood Hazard Management. IEEE Trans. Geosci. Remote Sens. 2007, 45, 1715-1725. [CrossRef]

50. Cohen, S.; Brakenridge, G.R.; Kettner, A.; Bates, B.; Nelson, J.; McDonald, R.; Huang, Y.-F.; Munasinghe, D.; Zhang, J. Estimating Floodwater Depths from Flood Inundation Maps and Topography. J. Am. Water Resour. Assoc. 2018, 54, 847-858. [CrossRef]

51. Scorzini, A.; Radice, A.; Molinari, D. A New Tool to Estimate Inundation Depths by Spatial Interpolation (RAPIDE): Design, Application and Impact on Quantitative Assessment of Flood Damages. Water 2018, 10, 1805. [CrossRef]

52. Ouma, Y.; Tateishi, R. Urban Flood Vulnerability and Risk Mapping Using Integrated Multi-Parametric AHP and GIS: Methodological Overview and Case Study Assessment. Water 2014, 6, 1515-1545. [CrossRef]

53. Walker, J.J.; Petrakis, R.E.; and Soulard, C.E. Implementation of a Surface Water Extent Model using Cloud-Based Remote Sensing-Code and Maps; U.S. Geological Survey: Reston, VA, USA, 2020. [CrossRef] 